\title{
Bone Marrow Aspiration Evaluation in Clinical Management of Anemia Among Low Socioeconomic Group In A Tertiary Care Hospital.
}

\author{
Dr. Johnsy Merla J. ${ }^{1},{ }^{*}$ Dr. Suresh Durai J. ${ }^{2}$, Dr. Shantaraman K. ${ }^{3}$ \\ ${ }^{1}$ Assistant Professor, ${ }^{2}$ Professor, ${ }^{3}$ Professor \& HOD, Dept. Of Pathology, Tirunelveli Medical College, \\ Tamilnadu, India. \\ *Corresponding Author : Dr. Suresh Durai.J.
}

\begin{abstract}
Bone marrow aspiration (BMA) is a relatively safe invasive procedure by which representative sample of bone marrow is obtained through a needle aspiration for diagnostic evaluations. A total of 331 cases of anemia were profiled during the study period. The age range of patients were from 10 to 81 years. The majority of the subjects was in the adolescent age group of $10-19$ years(20.54\%). A complete blood count and peripheral smear examination in these cases revealed 125(37.76\%) microcytic hypochromic anemia followed by 116(35.05\%) Dimorphic anemia,23(6.95\%)Pancytopenia, 23(6.95\%)leukemia,31 cases (9.37\%) macrocytic anemia, 2 haemolytic anemia and 11(3.32\%) were normocytic. These cases were further evaluated with bone marrow examination bone-marrow aspiration revealed 88 (26.59\%) erythroid hyperplasia with micronormoblastic and macronormoblastic maturation(Combined deficiency),56 ( 16.92\%) micronormoblastic maturation, 38 (11.48\%) megaloblastic maturation, 23 ( 6.95\%) Leukemia, Plasma cell myeloma 7(2.11\%), lymphoma 6 (1.81\%), hypoplastic marrow 5 (1.51\%), haemophagocytic Lymphohistiocytosis 4 (1.21\%),3 (0.91\%) myelodysplastic syndrome, 2 (0.60\%)cases of idiopathic thrombocytopenic purpura.In 22 (6.65\%) cases the marrow was reactive. The age, sex, peripheral smear study, bone marrow aspiration study and diagnosis were collated and statistically analyzed. A definite diagnosis of plasma cell myeloma,lymphoma and myelodysplastic syndrome was possible only with bone marrow evaluation. In our study, in $77 \%$ of cases a definite diagnosis of cause of anemia was arrived after bone marrow evaluation. 50\% of cases were diagnosed with megaloblastic anemia indicating an underlying B12 and folate deficiency.
\end{abstract}

Keywords: Anemia, Bone marrow aspiration, Cytology, Histopathology.

\section{Introduction}

Bone marrow examination is an important diagnostic tool in hematology.Bone marrow aspiration (BMA) is a relatively safe invasive procedure by which representative sample of bone marrow is obtained through a needle aspiration for diagnostic evaluations(1-4). The history of in vivo bone marrow examination dates back to 1876 when Mosler used a wood drill to aspirate bone marrow from a patient with leukaemia(2). Peripheral blood smear examination and other routine laboratory assays are not always sufficient for the diagnosis of various diseases which affect the blood and bone marrow. Patients with suspected marrow diseases whose diagnosis remain inconclusive after examination of the peripheral blood with complete blood count (CBC) and ancillary tests, require BMA. Bone marrow aspiration provides reliable information regarding bone marrow cellularity, its architecture and the stage of maturation of different blood cells(5). Bone marrow aspiration cytology is a proven method for the evaluation of hematologic conditions, storage disorders ,malignancies, and some chronic systemic conditions(6). Unexplained anemia among low socioeconomic group is often regarded as nutritional or anemia of chronic disease if the patient has an underlying disease.However a number of nonnutritional factors are known to cause anemia in such patients. We report here the profile of bone marrow aspiration cytology in a tertiary care hospital.

\section{Material And Methods}

The study was conducted at department of pathology, Tirunelveli medical college,Tamilnadu. The BMA cytology records from the Department of Pathology from January 2015 to December 2016 were reviewed in retrospect. A detailed history with relevant physical examination records for the presence of anemia, hepatosplenomegaly and lymphadenopathy were recorded. Complete blood count including hemoglobin, total and differential leukocyte count, platelet count, and blood indices were performed using automated hematology analyzer (Sysmex K21). Peripheral blood smear examination was done with Leishman and reticulocyte stain. Aspirations were performed after obtaining informed consent and documented. BMA procedures were performed using a standard unit protocol as adapted from ICSH guidelines $(1,7)$. Bone marrow was aspirated from posterior superior iliac crest under local anesthesia using lignocaine solution. In obese patients, sternum 
was used for aspiration. Salah bone marrow aspiration needle was used, and to avoid dilution of the yield by peripheral blood, only approximately $0.3 \mathrm{ml}$ bone marrow was aspirated. At the same time, peripheral blood was also obtained to complement information from the bone marrow aspiration cytology.Few smears were air dried and stained with Leishman stain. Others were fixed in methanol for 20 minutes. The fixed smears were stained with Wright - Giemsa stain. A complete clinical history from the available records including the presence of metabolic,hormonal and occupational diseases were assessed and excluded as a cause for anemia. The age, sex, peripheral smear study, bone marrow aspiration study and diagnosis were collated and statistically analyzed.

\section{Results}

A total of 331 cases of anemia were profiled during the study period. The age range of patients were from 10 to 81 years. The majority of the subjects was in the adolescent age group of $10-19$ years $(20.54 \%)$, followed by $18.43 \%$ of patients in $30-39$ years and $18.13 \%$ in $40-49$ years, with a male to female ratio of 1.2 : 1(Table 1\&Fig.1).

\begin{tabular}{|l|l|l|}
\hline AGE & NO OF PATIENTS & PERCENTAGE \\
\hline $10-19$ & 68 & 20.54 \\
\hline $20-29$ & 52 & 15.71 \\
\hline $30-39$ & 61 & 18.43 \\
\hline $40-49$ & 60 & 18.13 \\
\hline $50-59$ & 38 & 11.48 \\
\hline $60-69$ & 36 & 10.88 \\
\hline $70-79$ & 14 & 4.23 \\
\hline $80-89$ & 2 & 0.6 \\
\hline TOTAL & 331 & 100 \\
\hline
\end{tabular}

Table 1: Age distribution

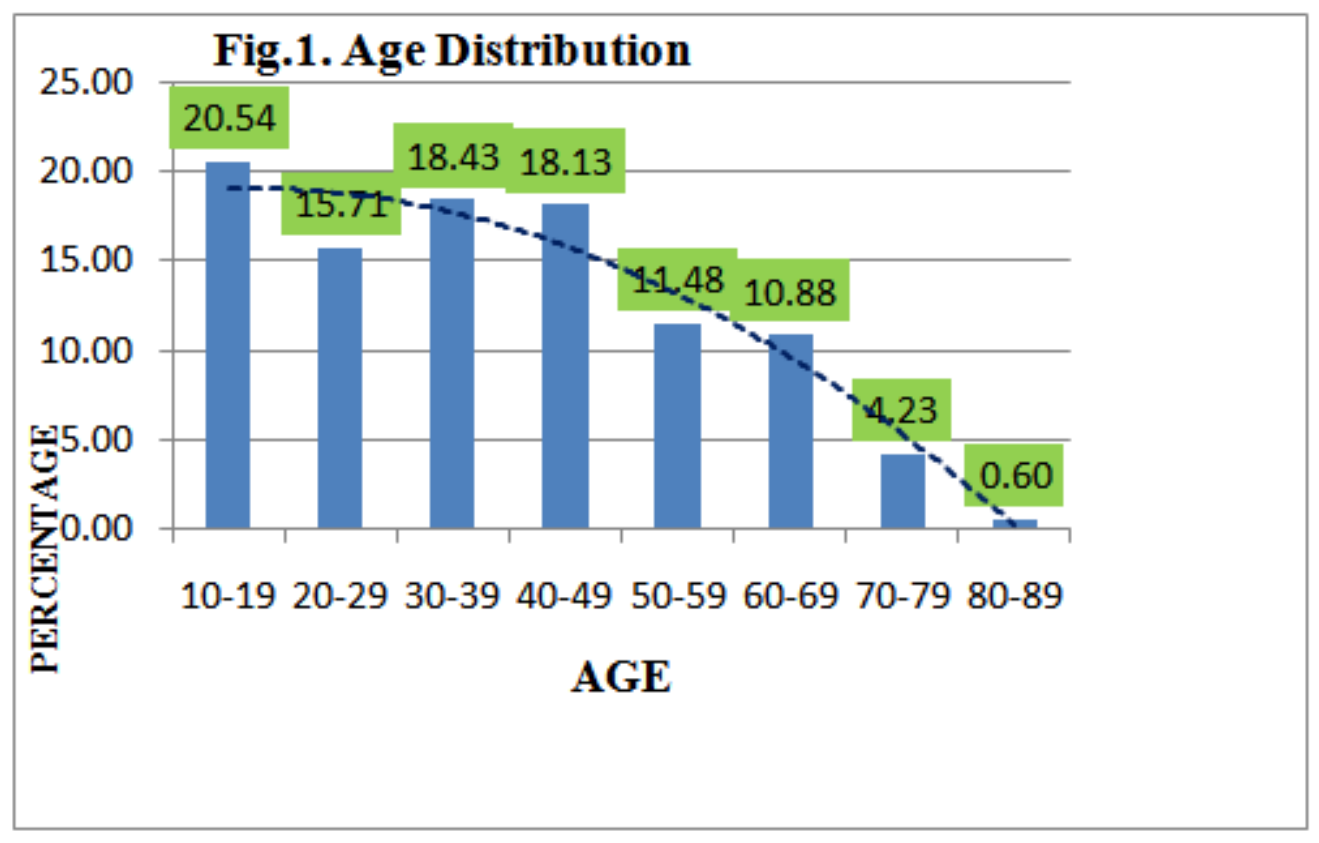

A complete blood count and peripheral smear examination in these cases revealed 125(37.76\%) microcytic hypochromic anemia(MCHC),116(35.05\%) Dimorphic anemia(DA),23(6.95\%)Pancytopenia (PAN), 23(6.95\%)leukemia,31 cases(9.37\%)macrocytic anemia,2 haemolytic anemia and 11(3.32\%) were normocytic(Table 2\& Fig.2).

\begin{tabular}{|l|l|l|}
\hline Diagnosis & No of paitents & Percentage \\
\hline Mchc & 125 & 37.76 \\
\hline Da & 116 & 35.05 \\
\hline Pan & 23 & 6.95 \\
\hline
\end{tabular}




\begin{tabular}{|l|l|l|} 
Ns & 11 & 3.32 \\
\hline Leukemia & 23 & 6.95 \\
\hline Macro & 31 & 9.37 \\
\hline Hemolytic & 2 & 0.60 \\
\hline Total & 331 & 100 \\
\hline
\end{tabular}

Table 2: Peripheral smear diagnosis

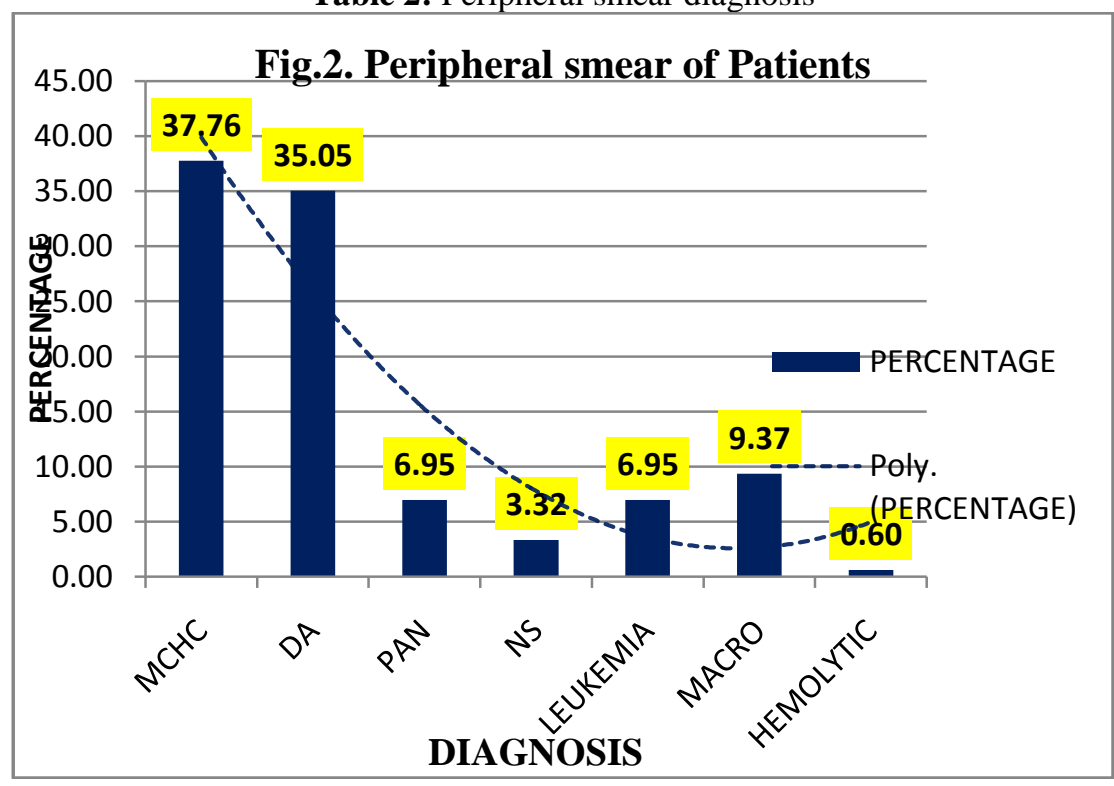

These cases were further evaluated with bone marrow examination and broadly categorized and analyzed. Material acquired was inadequate for interpretation or was obscured by blood and blood elements in $23.26 \%$ of the cases. The distribution of cases based on the final impression obtained after bone-marrow aspiration revealed 88 ( $26.59 \%)$ erythroid hyperplasia with micronormoblastic and macronormoblastic maturation(Combined deficiency),56 ( $16.92 \%)$ micronormoblastic maturation, 38 (11.48\%) megaloblastic maturation, 23 ( $6.95 \%)$ Leukemia, Plasma cell myeloma 7(2.11\%), lymphoma 6 (1.81\%), hypoplastic marrow 5 (1.51\%), haemophagocytic Lymphohistiocytosis $4(1.21 \%), 3(0.91 \%)$ myelodysplastic syndrome, $2(0.60 \%)$ cases of idiopathic thrombocytopenic purpura.In 22 (6.65\%) cases the marrow was reactive(Table 3\& Fig.3).

\begin{tabular}{|l|l|l|}
\hline Diagnosis & No Of Paitents & Percentage \\
\hline Micronormoblastic & 56 & 16.92 \\
\hline Micro \& Macro & 88 & 26.59 \\
\hline Megaloblastic & 38 & 11.48 \\
\hline Leukemia & 23 & 6.95 \\
& & \\
\hline Diluted & 77 & 23.26 \\
\hline Hypoplastic & 5 & 1.51 \\
\hline Haemophagocytic & 4 & 1.21 \\
\hline Plasmacellmyeloma & 7 & 2.11 \\
\hline Reactive Marrow & 22 & 6.65 \\
\hline Lymphoma & 6 & 1.81 \\
\hline Itp & 2 & 0.60 \\
\hline Mds & 3 & 0.91 \\
\hline Total & 331 & 100 \\
\hline
\end{tabular}

Table 3: Bone marrow aspiration cytology diagnosis 


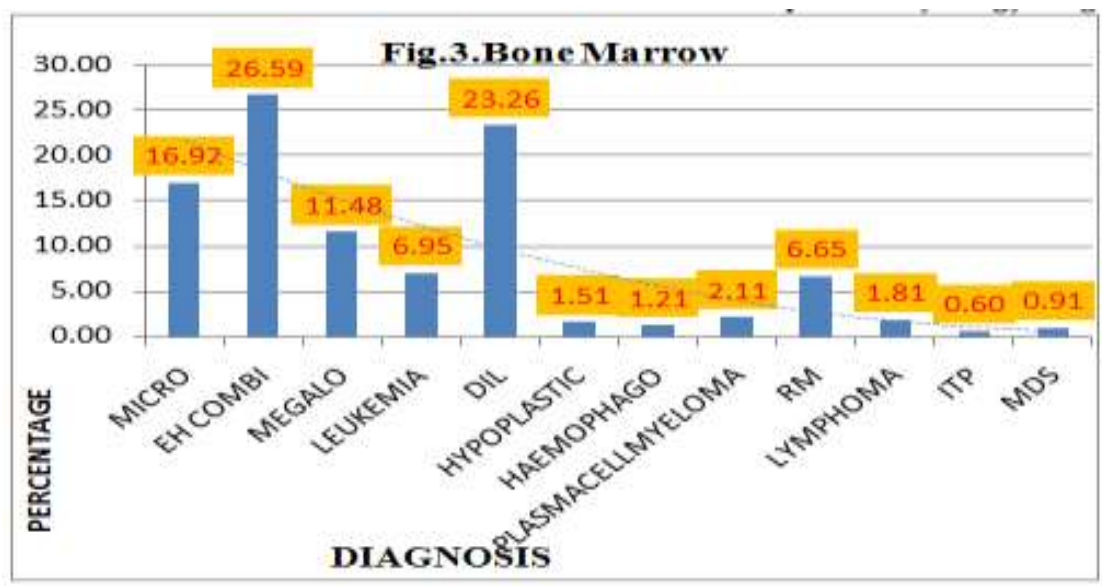

The distribution of micronormoblastic maturation (Fig.4)was higher in the age group of 10- 19 years $(26.32 \%)$,followed by $20-29(22.81 \%)$ and $30-39$ years $(21.05 \%)$ and equally distributed among males $(50 \%)$ and females $(50 \%)$. The distribution of erythroid hyperplasia with micronormoblastic and macronormoblastic maturation- Combined deficiency(Fig.5)was higher in the age group of 40- 49 years(22.73\%).The distribution was similar 19.32\% in adolescent and 30-39 age groups, followed by 20-29 age group(18.18\%).The distribution was higher in males $(66 \%)$ compared to females (34\%). The distribution of megaloblastic maturation (Fig.6)was higher in adolescent and 40-49 age groups(23.68\%), followed by 30-39 (15.79\%) and 20-29 years(13.16\%) (Table 4) and was more common in males(76.31\%) than females(23.68\%). Comparing the bone-marrow aspirate findings with that of the peripheral blood smear showed that in cases reported as dimorphic anemia on peripheral blood smear (116 cases) dimorphic maturation was confirmed in 54 of the cases and 25 cases had megaloblastic maturation. In cases with microcytic hypochromic blood picture (125 cases), 39 cases showed micronormoblastic maturation, 25 showing dimorphic maturation,

followed by normoblastic maturation 13 and megaloblastic maturation(Fig.7) 11 cases. In 23 cases of pancytopenia, five of the patients were diagnosed with plasma cell myeloma.Assessment of normocytic normochromic blood picture (11 cases), one case was of micronormoblastic maturation, 6 were reactive marrow. Of the 23cases diagnosed as leukemia on peripheral blood smear, 22 were confirmed for malignancy on bone-marrow examination. Eight cases of chronic myeloid leukemia, 7 cases of acute myeloid leukemia(Fig.8), and 8 cases of acute Lymphocytic leukemia(Fig.9) were confirmed. Idiopathic thrombocytopenia was diagnosed in two out of four cases evaluated for thrombocytopenia. $<1 / 5$ of cases that presented with pancytopenia showed marrow hypoplasia.

\begin{tabular}{|l|l|l|l|l|l|l|}
\hline \multirow{2}{*}{ Age } & \multicolumn{2}{|l|}{$\begin{array}{l}\text { Micro } \\
\text { Normoblastic }\end{array}$} & $\begin{array}{l}\text { Combined } \\
\text { Deficiency }\end{array}$ & \multicolumn{2}{l|}{ Megaloblastic } \\
\cline { 2 - 7 } & Cases & $\%$ & Cases & $\%$ & Cases & $\%$ \\
\hline $10-19$ & 15 & 26.32 & 17 & 19.32 & 9 & 23.68 \\
\hline $20-29$ & 13 & 22.81 & 16 & 18.18 & 5 & 13.16 \\
\hline $30-39$ & 12 & 21.05 & 17 & 19.32 & 6 & 15.79 \\
\hline $40-49$ & 5 & 8.77 & 20 & 22.73 & 9 & 23.68 \\
\hline $50-59$ & 4 & 7.02 & 6 & 6.82 & 4 & 10.53 \\
\hline $60-69$ & 4 & 7.02 & 10 & 11.36 & 2 & 5.26 \\
\hline $70-79$ & 2 & 3.51 & 1 & 1.14 & 3 & 7.89 \\
\hline $80-89$ & 1 & 1.75 & 1 & 1.14 & 0 & 0.00 \\
\hline Total & 56 & 100 & 88 & 100 & 38 & 100 \\
\hline
\end{tabular}

Table 4: Bone marrow aspiration cytology diagnosis 

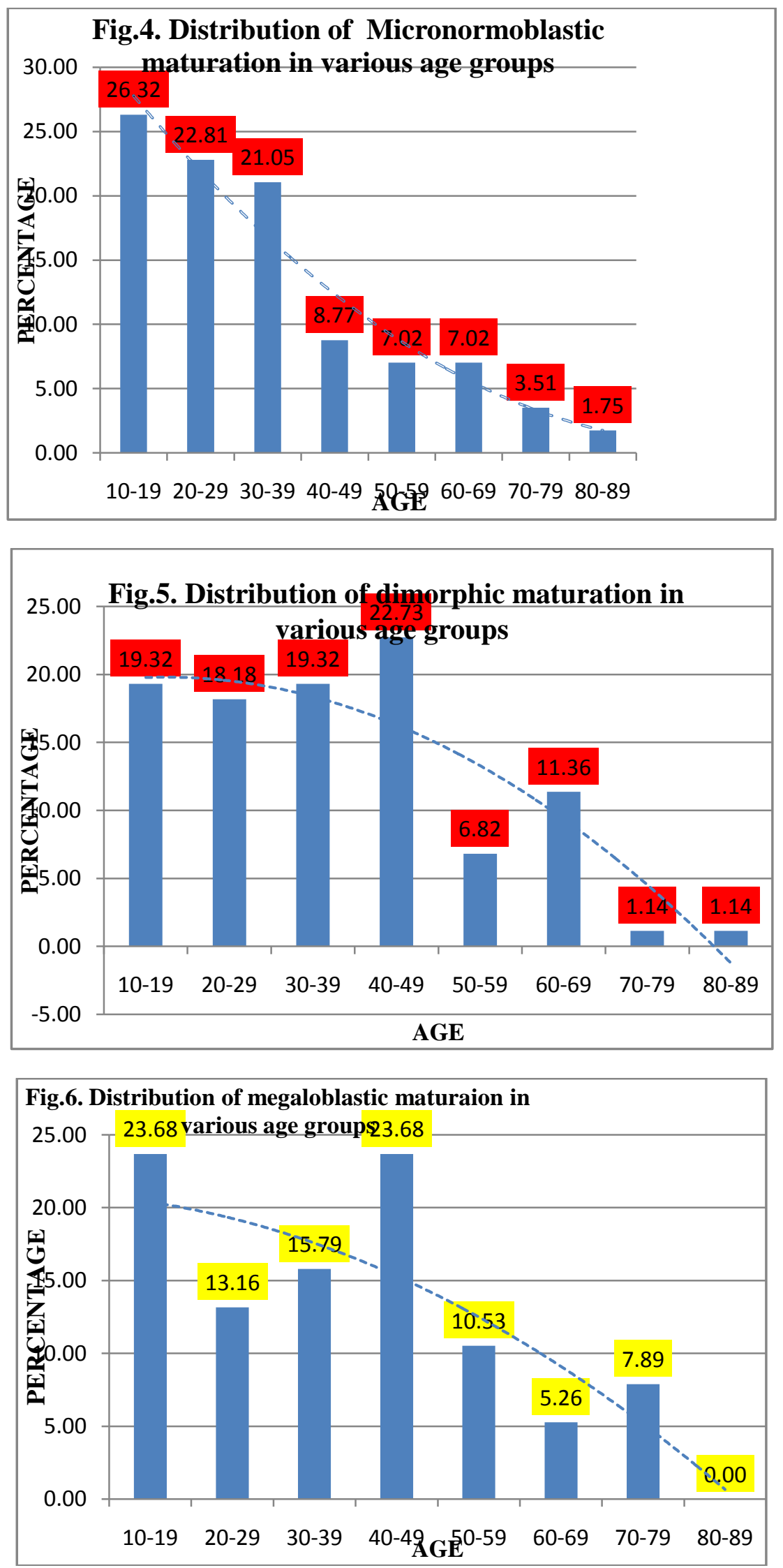

Dyserythropoietic changes such as multinuclearity,nuclear budding, basophilic stippling, Howell-Jolly bodies, and cytoplasmic vacuolation were seen in 20 cases. Of these majority of cases were seen in cases of 
dimorphic maturation followed by megaloblastic maturation. Myelodysplastic syndrome was diagnosed in 2 cases(Table 5). A definite diagnosis of plasma cell myeloma,lymphoma and myelodysplastic syndrome was possible only with bone marrow evaluation.

\begin{tabular}{|c|c|c|c|c|c|c|c|c|c|c|c|c|c|}
\hline \multirow[b]{2}{*}{ 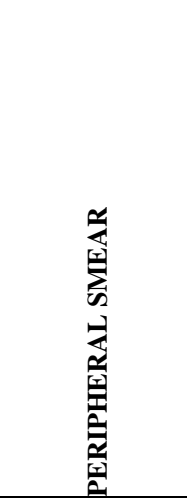 } & \multicolumn{13}{|c|}{ BONE MARROW ASPIRATION CYTOLOGY DIAGNOSIS } \\
\hline & 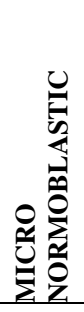 & 岂 & 岂 & 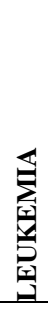 & 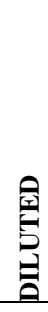 & 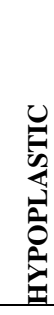 & 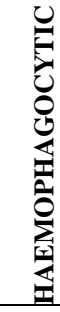 & 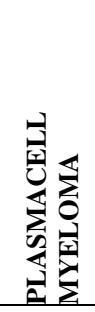 & 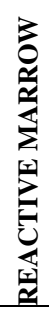 & 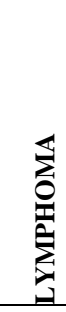 & $\underline{E}$ & $\stackrel{\tilde{E}}{\Sigma}$ & 嵑 \\
\hline МCHC & 39 & 25 & 11 & 1 & 25 & 3 & 2 & 1 & 13 & 4 & 1 & 0 & 125 \\
\hline DA & 15 & 54 & 25 & 1 & 17 & 1 & 1 & 0 & 1 & 0 & 0 & 1 & 116 \\
\hline PAN & 0 & 2 & 2 & 0 & 12 & 1 & 1 & 5 & 0 & 0 & 0 & 0 & 23 \\
\hline NS & 1 & 0 & 0 & 0 & 2 & 0 & 0 & 0 & 6 & 0 & 1 & 1 & 11 \\
\hline LEUKEMIA & 0 & 0 & 0 & 20 & 1 & 0 & 0 & 0 & 0 & 2 & 0 & 0 & 23 \\
\hline MACRO & 0 & 7 & 0 & 1 & 19 & 0 & 0 & 1 & 2 & 0 & 0 & 1 & 31 \\
\hline HEMOLYTIC & 1 & 0 & 0 & 0 & 1 & 0 & 0 & 0 & 0 & 0 & 0 & 0 & 2 \\
\hline TOTAL & 56 & 88 & 38 & 23 & 77 & 5 & 4 & 7 & 22 & 6 & 2 & 3 & 331 \\
\hline
\end{tabular}

Table 5: Cross tabulation of peripheral smear diagnosis and bone marrow aspiration cytology diagnosis

\section{Discussion}

Bone-marrow is one of the most widely distributed organs of the body. It is the principal site of hematopoiesis. Bone marrow aspiration is used to diagnose, confirm, and/or stage hematologic malignancies. It helps in evaluating anemias,cytopenias, leukocytosis, thrombocytosis, and iron status and also a diagnostic tool in nonhematological disorders such as systemic infections and storage disorders. Cytopenias commonly results from accelerated peripheral destruction of blood cells as in underproduction or maturation defects, autoimmune disease(8) Most times, if the cause is not found peripherally, there is need for examination of the bone marrow, the site of haematopoiesis. BMA specimens are also relevant for additional investigations including molecular studies, cytogenetic, cytochemistry, flow cytometry/Immunophenotyping, microbiological studies and others $(1,2,4)$.

Bone marrow evaluation is indicated in all forms of chronic anemias.It may be indicated in cytopenias of other cell lineages also.A study in Nigeria, Egesie et al. identified anemia as a major indication for BMA(9). Studies by Damulak, Damen(10) and Tripathy et al(11) showed anemia as the most common indication for BMA cytology.A study conducted by Mirzai et al.,(12) on 1154 cases showed pancytopenia for evaluation to be the most common indication. Another study by Bashawri(13) on a total of 1813 cases showed that evaluation of acute leukemias and staging of lymphomas were the most common indications ( $22.2 \%$ and $15.2 \%$, respectively). This discrepancy can be explained by the higher incidence of unexplained anemias among the people in rural areas in our study.

In our study, among the various types of anemia, erythroid hyperplasia with micro and macronormoblastic maturation (combined deficiency) was the most common as in many other studies. Hence this study reveals that $50 \%$ of cases had megaloblastic anemia indicating an underlying B12 and folate deficiency The peak incidence was found in the age-group of 40-49 years. The incidence is less (15\%) in older age groups 5th to $8^{\text {th }}$ decade. In the research done by Parajuli et al, it was the second most common cause of anemia overall(14). The high prevalence of dimorphic maturation is explained by the occurrence of nutritional deficiencies in rural areas. Nutritional deficiencies of iron and folate commonly occur together, more commonly in pregnant women. Iron deficiency occurring concurrently with megaloblastic anemia has been reported in many studies. In some instances, the megaloblastosis may be intermediate in degree but may become more marked after administration of iron, and some cases of severe dimorphic anemia do not respond initially to iron therapy, probably owing to concomitant severe folate and occasionally Vitamin B12 deficiency(15).Other 
patterns of bone marrow diagnosis in the index study included micrnormoblastic and megaloblastic maturation. In our study,isolated iron deficiency was equally distributed among males(50\%) and females(50\%) whereas combined deficiency of B12 and folate appear to be more common in males than females.In Studies by Ranabhat $\mathrm{S}$ et al (16) and Chand $\mathrm{N}$ et al (17) the diseases were more common in females. According to a study conducted by Gayathri and Rao(18) the most common cause of pancytopenia was megaloblastic anemia (74\%).In our study,among the cases investigated for pancytopenia 2 cases each of combined deficiency and megaloblastic maturation and 5 cases of plasma cell myeloma were diagnosed.

Adolescent age group showed highest number of micronormoblastic maturation of RBCs in bone marrow.The fact that a significant number (1/5) of microcytic hypochromic smears showed an underlying megaloblastic maturation in bone marrow confirms the fact that RBC indices and peripheral smear does not always reflect the underlying cause of anemia.

It may seem paradoxical that leukemias can present with peripheral pancytopenias. Most of the patients present in fibrotic and postproliferative stage of the disease. The fibrotic stage often presents with anemia and thrombocytopenia due to accompanying splenomegaly. The white blood cell count, on the other hand, can be low, normal or elevated. As fibrosis becomes more severe, the patients' cytopenias worsen(19) In 9\% of cases though $\mathrm{CBC}$ and peripheral smear showed pancytopenia,bone marrow aspiration revealed marrow hypoplasia in $2 \%$ of cases and five cases revealed hematological malignancy. Leukemia as a group was the most common malignant disorder $(15 \%)$ and acute myeloblastic leukemia was found to be the most common type of leukemia in our study as in other studies(20-21). In contrast, acute lymphoblastic leukemia (ALL) was found to be the most common type of leukemia in a couple of studies $(22,23)$ Multiple myeloma was found to be the secondmost common malignant disease. Immune thrombocytopenic purpura (ITP) is an autoimmune disease. Like all autoimmune diseases, ITP is more common in women(24). The proportion of ITP cases in our study was $16.4 \%$.

\section{Conclusion}

Bone marrow aspiration cytology is a safe invasive technique.BMA should not be a first line investigation. It is often indicated after initial evaluation of the peripheral blood and other ancillary tests.Although BMA should be performed only when there is a defnite clinical indication, it is a useful technique in the diagnoses and management of a wide range of underlying hematological and nonhematological diseases.In our study,in $77 \%$ of cases a definite diagnosis of cause of anemia was arrived after bone marrow evaluation. $50 \%$ of cases were diagnosed with megaloblastic anemia indicating an underlying B12 and folate deficiency.In $9 \%$ of cases though CBC and peripheral smear showed pancytopenia,bone marrow aspiration revealed marrow hypoplasia just in $2 \%$ of cases. However, the material acquired was inadequate for interpretation or was obscured by blood and blood elements in $23.26 \%$ of the cases. In conclusion, this study shows that bone-marrow aspiration is an extremely valuable diagnostic tool in the confirmation of diagnoses as well as explaining the cause for chronic anemia and pancytopenia.

\section{References}

[1]. Bain BJ. Bone marrow aspiration. J Clin Pathol 2001; 54: 657-63.

[2]. Ryan DH, Felgar RE. Examination of the marrow. In: Lichtman MA, Kipps TJ, et al (eds). William's haematology 7ed. New York, McGraw Hill 2006; 3: 21-31.

[3]. Gluckman E. Choice of the donor according to HLA typing and stem cell source. Apperley J, Carreras E, Gluckman E, Masszi T (eds). Haemotopoietic Stem cell transplantation. EBMT Handbook 6ed; 2012; 6: 90-107.

[4]. Bolan CD, Kurlander RJ, Schechter GP. Interpretation of standard hematologic tests. In: Rodgers GP, Young NS. The Bethesda handbook of clinical hematology. 3ed. 27: pp405- 426 .

[5]. Bain BJ. Bone marrow biopsy morbidity: Review of 2003. J Clin Pathol 2005;58:406-8.

[6]. Malempati S, Joshi S, Lai S, Braner D, Tegtmeyer K. Bone marrow aspiration and biopsy. N Engl J Med. $2009 ; 361: e 28$.

[7]. Lee SH, Erber WN, Porwit A, et al: ICSH guidelines for the standardization of bone marrow specimens and reports. Int J Lab Hematol 2008; 30: $349-364$.

[8]. Adewoyin AS, Nwogoh B. Peripheral Blood film: a review. Annals of Ibadan Postgraduate Medicine 2014; 12 (2): 71 - 79

[9]. Egesie OJ, Joseph DE, Egesie UG, Ewuga OJ. Epidemiology of anemia necessitating bone marrow aspiration cytology in Jos. Niger Med J 2009; 50: $61-63$.

[10]. Damulak OD, Damen JG. Diagnostic outcome of bone marrow aspiration in a new centre in Nigeria. Glob Adv Res J Med Sci 2012;1:166-71.

[11]. Tripathy S, Dudani S. Comparative evaluation of simultaneous bone marrow aspiration and trephine biopsy. Experience from routine haematology practice. Indian J Clin Pract 2013;24:5.

[12]. Mirzai AZ, Hosseini N, Sadeghipour A. Indications and diagnostic utility of bone marrow examination in different bone marrow disorders in Iran. Lab Hematol 2009;15:38-44.

[13]. Bashawri LA. Bone marrow examination. Indications and diagnostic value. Saudi Med J 2002;23:191-6

[14]. Parajuli S, Tuladhar A. Correlation of bone marrow aspiration and biopsy findings in diagnosing hematological disorders - a study of 89 cases. Journal of Pathology of Nepal. 2014;4:534-38.

[15]. Weinzierl EP, Arber DA. Bone marrow evaluation in new-onset pancytopenia. Hum Pathol 2013;44:1154-64.

[16]. Ranabhat $\mathrm{S}$ et al. Bone marrow aspiration cytology in the diagnosis of hematologic and non-hematologic diseases in a multispecialty hospital in Nepal Int J Res Med Sci. 2017 Mar;5(3):922-926 
[17]. Chand N, Singla S, Sangwan K, Bansal H, Bajwa D, Sharma A, et al. Diagnosis of hematological and non-hematological disorders using bone marrow aspiration and trephine biopsy (a correlating study). Res J Pharm, Bio Che Sci. 2015;6(4):125.

[18]. Gayathri BN, Rao KS. Pancytopenia: A clinico hematological study. J Lab Physicians 2011;3:15-20.

[19]. Bick RL. Anemia of malignancy. Adv Exp Med Biol 1995;369:195-200.

[20]. Pudasaini S, Prasad KBR, Rauniyar SK, Shrestha R, Gautam K, Pathak R, et al. Interpretation of bone marrow aspiration in hematological disorder. J Patho Nepal. 2012;2:309-12.

[21]. Kibria SG, Islam MDU, Chowdhury ASMJ. Prevalence of hematological disorder: a bone marrow study of 177 cases in a private hospital at Faridpur. Faridpur Med Coll J. 2010;5:11-3.

[22]. Egesie OJ, Joseph DE, Egesie UG, Ewuga OJ. Epidemiology of anemia necessitating bone marrow

[23]. aspiration cytology in Jos. Niger Med J. 2009;50:61-4.

[24]. Rahim F, Islam AI, Hussain S, Khan M, Khattack TAK. Spectrum of hematologic disorders in children observed in 424 consecutive bone marrow aspirations/biopsies. Pak J Med Sci. 2005;21(4):276-9.

[25]. Andrès E. What impact for sex difference on immune thrombocytopenic purpura? Women Health Open J. 2016;2(1):e1-e3

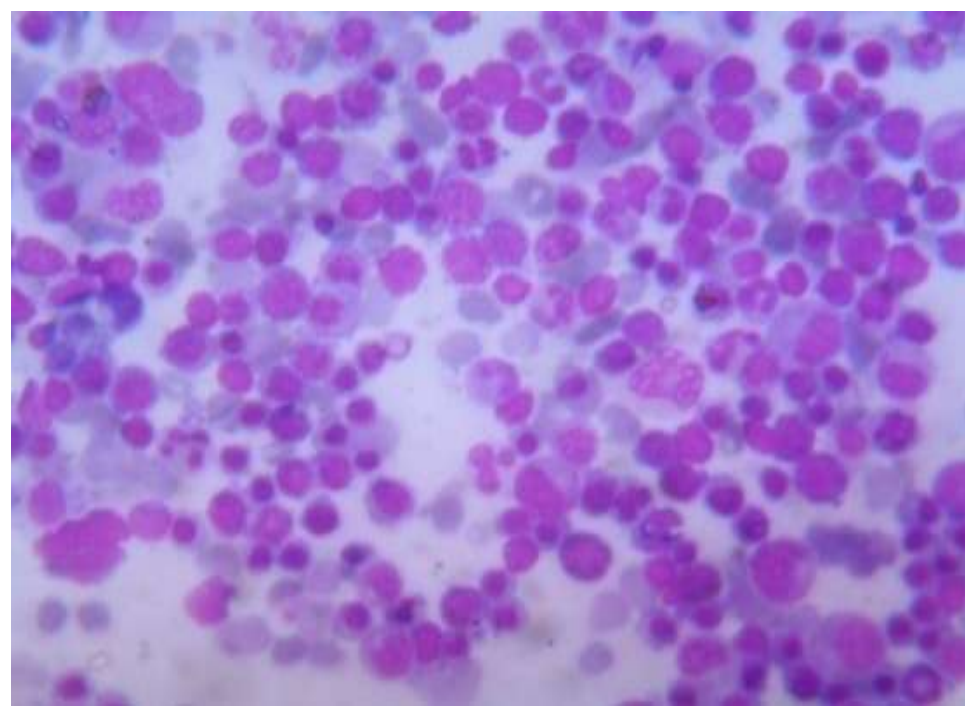

Fig.7: Photomicrograph of a bone marrow smear showing Megaloblastic marrow maturation. (Leishman's stain.x400)

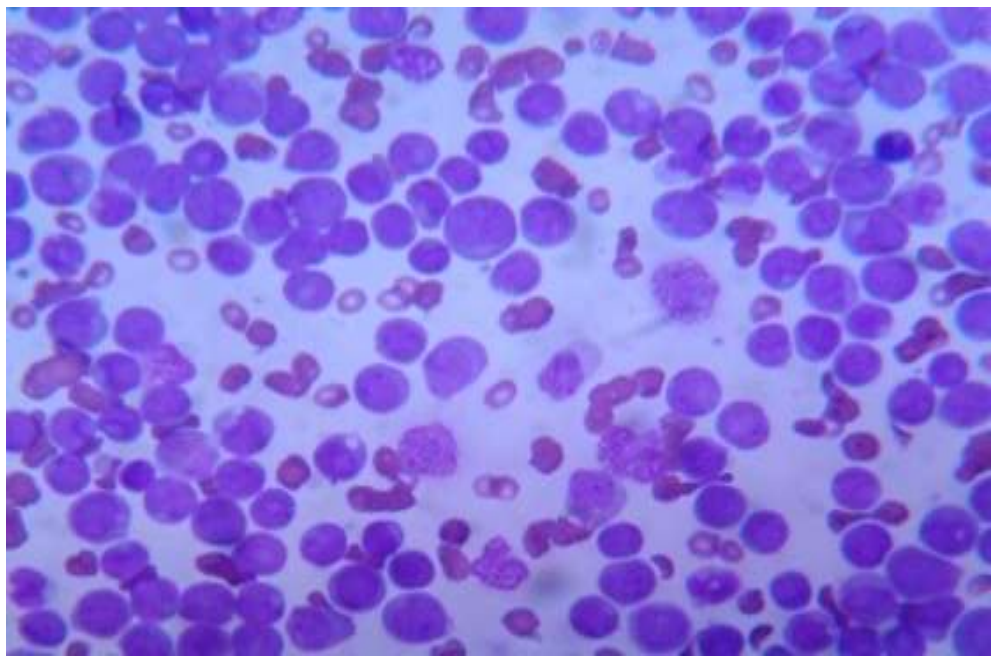

Fig.8. Photomicrograph of a bone marrow smear showing myeloblasts in a case of AML.

(Leishman's stain.x400) 


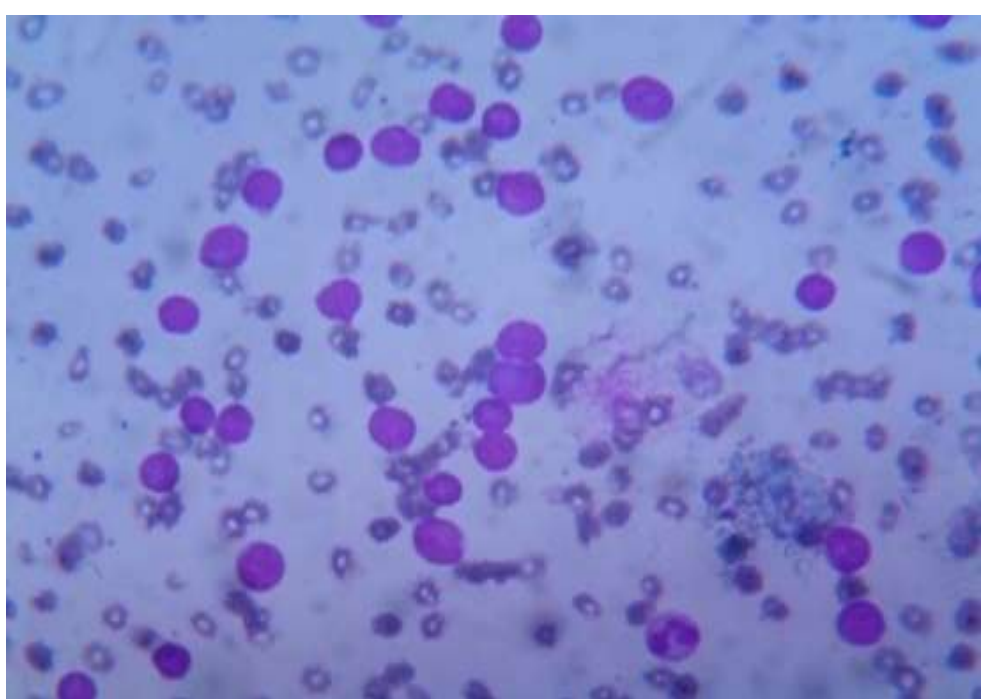

Fig.9: Photomicrograph of a bone marrow smear showing ALL.(Leishman's stain.x400)

Dr. Johnsy Merla.Dr. Suresh Durai J, Dr. Shantaraman K. "Bone Marrow Aspiration Evaluation in Clinical Management of Anemia Among Low Socioeconomic Group In A Tertiary Care Hospital." IOSR Journal of Dental and Medical Sciences (IOSR-JDMS) 16.7 (2017): 89-97. 